\title{
Synthesis and Characterization of Oxide Nanoparticles by Plasma Assisted Spray Pyrolysis
}

\author{
Takayuki Kodera, Hajime Horikawa, Takahiro Nakamura, \\ Kenichi Myoujin and Takashi Ogihara \\ University of Fukui, 9-1 Bunkyo 3, Fukui-shi, Fukui, 910-8507 Japan \\ Fax: 81-0776-27-8624, e-mail: ogihara@matse.fukui-u.ac.jp
}

\begin{abstract}
Various oxide nano-sized powders were successfully prepared by ultrasonic spray pyrolysis using arc plasma under the air atmosphere. Particle size, morphology, crystal phase and crystallinity of as-prepared powders were characterized by SEM and XRD. They had spherical morphology with narrow size distribution.
\end{abstract}

Key words: spray pyrolysis, oxide, plasma, nanoparticles

\section{INTRODUCTION}

Now, nano-sized oxide particles are noted as starting materials in electronic device, catalyst, filler and energy material. To achieve the formation of nano-sized particles, various solution technique such as sol-gel and hydrothermal and gas phase reaction have been developed. Spray pyrolysis technique [1-3] is one of solution technique and has the following potential advantage : (1) as-prepaerd particles are spheres with a high surface area, (2) chemical homogeneity is enhanced relative to solid state reaction, (3) oxide powders can be directly prepared and take much shorter than that is required for solid state reaction and the sol-gel method. It is well-known that ultrasonic spray pyrolysis has been applied to preparation of submicrometer oxide precursor particles with narrow sized distribution.

However it was difficult to prepare nano-sized powders by spray pyrolysis using electrical furnace because the break down sized of droplets generated by ultrasonic is limited at less than $1000^{\circ} \mathrm{C}$. Okuyama et al $[4,5]$ reported that oxide nanoparticles could be obtained by salt-assisted spray pyrolysis.

On the other hand, we have been offered novel nano-sized oxide powders preparation system [6] in which the mist of starting solution was pyrolyzed over
$7000{ }^{\circ} \mathrm{C}$ by arc plasma under air atmosphere.

In this paper, single and multicomponent oxide powders such as $\mathrm{MgO}, \mathrm{BaTiO}_{3}$ and $\mathrm{LiCo}_{1 / 3} \mathrm{Ni}_{1 / 3} \mathrm{Mn}_{1 / 3} \mathrm{O}_{2}$ were synthesized by spray pyrolysis using arc plasma and their particle characteristics were also investigated.

\section{EXPERIMENTAL PROCEDURE}

Magnesium nitrate was used as starting solution of $\mathrm{MgO}$. Barium nitrate and titanium tetraisopropoxide were used as starting solution of $\mathrm{BaTiO}_{3}$. Titanium tetraisopropoxide was dissolved in water by using nitric acid or citric acid because titanium tetraisopropoxide was easily hydrolyzed to form hydroxide in the water. Metal carboxyl acid and lithium nitrate were used as the starting solution of $\mathrm{LiCo}_{1 / 3} \mathrm{Ni}_{1 / 3} \mathrm{Mn}_{1 / 3} \mathrm{O}_{2}$. These were dissolved in water at $25^{\circ} \mathrm{C}$. The concentration of starting solution ranged from 0.1 to $0.5 \mathrm{~mol} / \mathrm{L}$.

The schematic diagram of ultrasonic spray pyrolysis apparatus with arc plasma was shown in Fig.1. The apparatus consisted of mist box, drying furnace, plasma reactor and powder collector. The starting solution was misted at $2.4 \mathrm{MHz}$ by an ultrasonic nebulizer (Honda Electronics, HM-2412) in mist box and dried in drying furnace at $200^{\circ} \mathrm{C}$. After drying, the mist was introduced into plasma reactor by air carrier gas. The flow rate

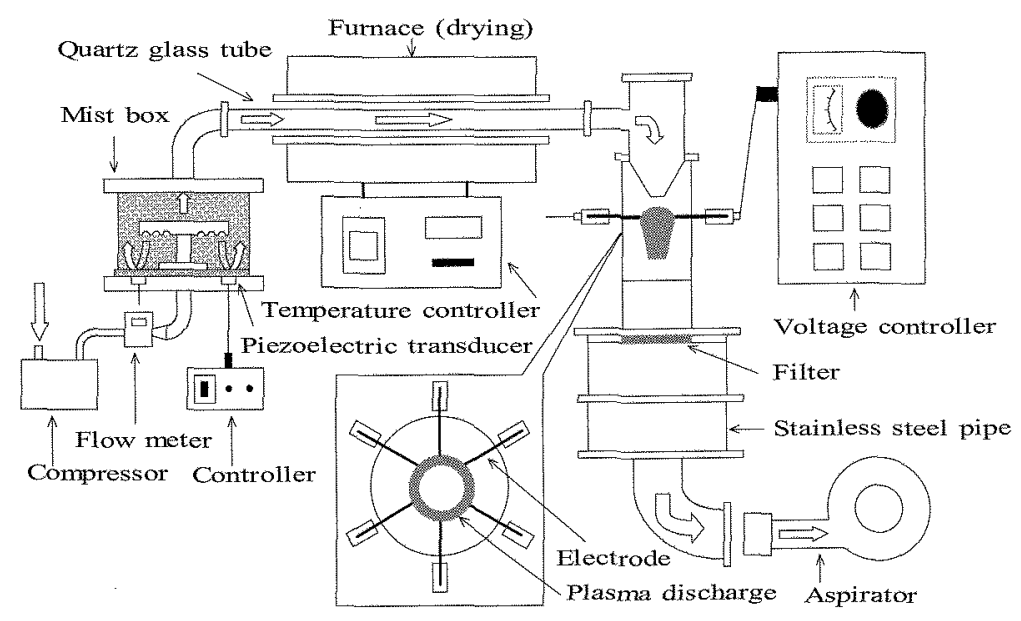

Fig.1. Schematic diagram of apparatus 


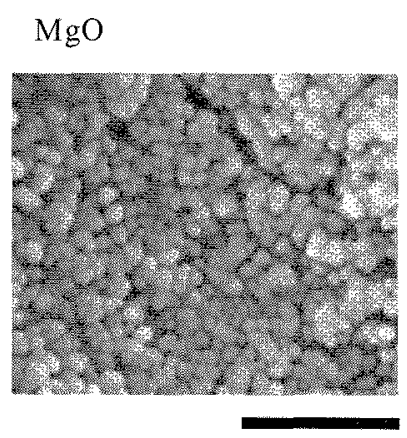

$\mathrm{BaTiO}_{3}$

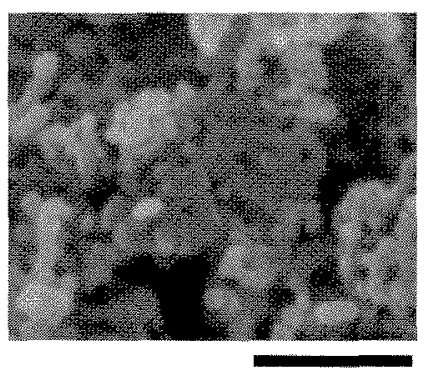

$\mathrm{LiCo}_{1 / 3} \mathrm{Ni}_{1 / 3} \mathrm{Mn}_{1 / 3} \mathrm{O}_{2}$

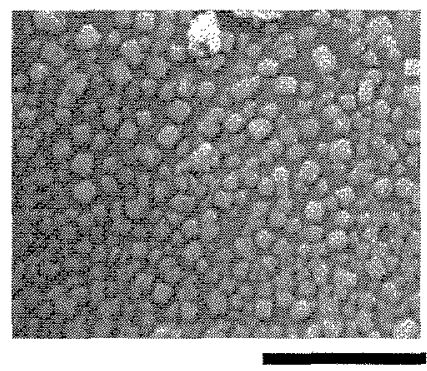

Fig.2 SEM photographs of as-prepared powders $(\mathrm{bar}=1 \mu \mathrm{m})$

ranged from 1 to $10 \mathrm{~L} / \mathrm{min}$. The mist was continuously pyrolyzed by arc plasma under an air atmosphere. The pyrolysis temperature was adjusted by voltage controller and ranged from 7000 to $10000^{\circ} \mathrm{C}$. Oxide precursor nanoparticles were collected using a collision type filter in powder collector. However, many particles passed the mesh because the mesh size of filter was barely large than the particle size.

Crystal phase of as-prepared powders and calcined powders was identified by powder X-ray diffraction (XRD, Shimadzu, XRD-6100) using CuKa radiation. Particle size and morphology were determined by scanning electron microscope (SEM, Hitachi, S-2300). The average particle size was determined by randomly sampling 200 particles from SEM photographs. The particle surface was measured by DTA-TG. Specific surface area of as-prepared powders was measured by BET method using $\mathrm{N}_{2}$ adsorption (SSA, Shimadzu, Tristar-3000). The chemical composition of as-prepared powders was determined by atomic adsorption spectrum analysis (AAS, Shimadzu, AAS-6800). Dielectric properties of $\mathrm{BaTiO}_{3}$ ceramics were measured by LCR meter (Kokuyo Denki, KC-537) at $100 \mathrm{kHz}$. Lithium secondary battery was produced by $\mathrm{LiCo}_{1 / 3} \mathrm{Ni}_{1 / 3} \mathrm{Mn}_{1 / 3} \mathrm{O}_{2}$ (cathode) and $\mathrm{Li}$ sheet (anode). Electrochemical properties of $\mathrm{LiCo}_{1 / 3} \mathrm{Ni}_{1 / 3} \mathrm{Mn}_{1 / 3} \mathrm{O}_{2}$ were measured by battery tester (Hosen BTS-2005). The charge/discharge capacity and cycle life were investigated.

\section{RESULTS AND DISCUSSION}

The production capacity of as-prepared powders was about $0.1 \mathrm{~g} / \mathrm{h}$ when the solution concentration was
$0.1 \mathrm{~mol} / \mathrm{L}$. The yield of as-prepared powders was about $10 \%$. This resulted in low collecting performance of filter used in synthesis. Figure 2 shows typical SEM photographs of typical $\mathrm{MgO}, \mathrm{BaTiO}_{3}$ and $\mathrm{LiCo}_{1 / 3} \mathrm{Ni}_{1 / 3} \mathrm{Mn}_{1 / 3} \mathrm{O}_{2}$ nanoparticles, respectively. They had spherical morphology with narrow size distribution. The average size of as-prepared particles determined by SEM photographs was less than $100 \mathrm{~nm}$ in all samples. It was found that the particle size of as-prepared powders was smaller than those obtained by ultrasonic spray pyrolysis using electric furnace. However, the particle size was not changed although the starting solution concentration was increased up to $0.5 \mathrm{~mol} / \mathrm{L}$.

On the other hand, the geometrical standard deviation of their average size ranged from 1.3 to 1.5 regardless of starting solution concentration. It was found that few $\mathrm{wt} \%$ of water was contained in all as-prepared powders from DTA-TG analysis. About $10 \mathrm{wt} \%$ of undecomposed nitrate was also contained in $\mathrm{MgO}$ nanopowders. SSA of as-prepared powders was $10-20 \mathrm{~m}^{2} / \mathrm{g}$. The chemical composition of as-prepared powders determined by AAS was good agreement with that of starting solution composition.

The crystal phase and crystallinity of as-prepared powders and calcined powders were identified by XRD. Figure 3 shows XRD patterns of as-prepared powders and calcined powders. XRD revealed that the crystallinity of as-prepared $\mathrm{MgO}, \mathrm{BaTiO}_{3}$ and $\mathrm{LiCo}_{1 / 3} \mathrm{Ni}_{1 / 3} \mathrm{Mn}_{1 / 3} \mathrm{O}_{2}$ powders was very low and the phase of barium carbonate was also observed in $\mathrm{BaTiO}_{3}$. The crystallinity of as-prepared powders was not improved although pyrolysis temperature was increased
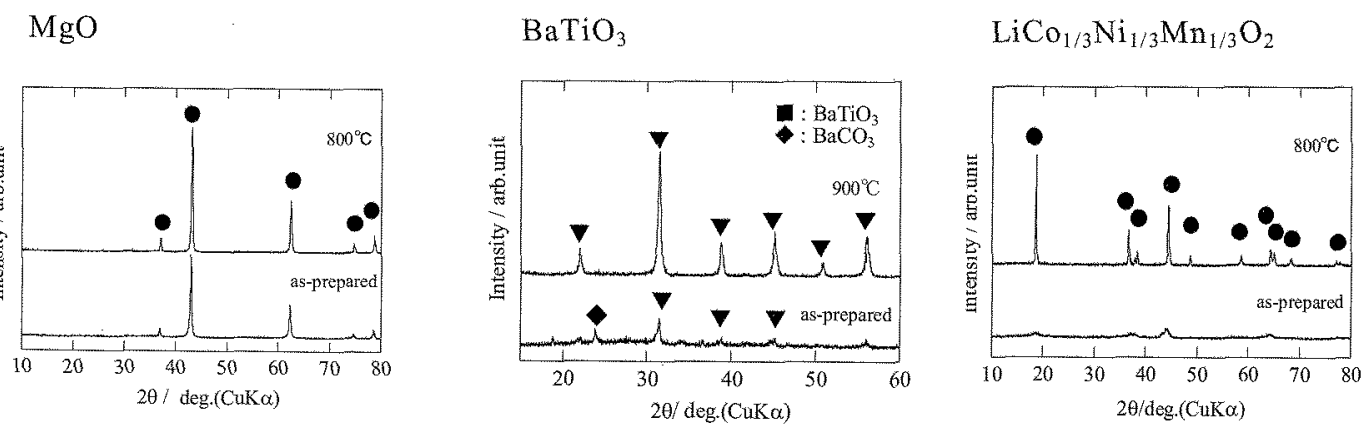

Fig.3. XRD patterns of as-prepared and calcined powders 
from 7000 to $10000^{\circ} \mathrm{C}$. This resulted in the very short residence time of mist in the plasma reactor. The residence time was few second in the plasma reactor. After the calcination at more than $800^{\circ} \mathrm{C}$, the crystallinity of them became higher than that of as-prepared powders. The phase of barium carbonate also disappeared in $\mathrm{BaTiO}_{3}$. Chemical analysis revealed that $\mathrm{Ba} / \mathrm{Ti}$ ratio of as-prepared powders was agreement with starting solution component. $5 \%$ particle size of $\mathrm{BaTiO}_{3}$ particles decreased by the calcination at more than $800^{\circ} \mathrm{C}$ and as-prepared particles were also nonaggregated. The sinterability of $\mathrm{BaTiO}_{3}$ nanopowders was compared with commercial $\mathrm{BaTiO}_{3}$ (KCM corporation, The average size of $\mathrm{BaTiO}_{3}$ particles was $240 \mathrm{~nm}$.) powders. The relative density of $\mathrm{BaTiO}_{3}$ nanopowders was $92 \%$ at $1200^{\circ} \mathrm{C}$. That of commercial $\mathrm{BaTiO}_{3}$ powders was $80 \%$. It was found that $\mathrm{BaTiO}_{3}$ powder obtained by aerosol plasma pyrolysis was sintered in lower temperature compare with commercial $\mathrm{BaTiO}_{3}$ powders because the average size of $\mathrm{BaTiO}_{3}$ particles obtained by aerosol plasma pyrolysis was very small. The dielectric constant and $\tan \delta$ of $\mathrm{BaTiO}_{3}$ ceramics obtained from nanopowders was about 2000 and 0.025 at $25^{\circ} \mathrm{C}$, respectively.

Figure 4 shows the discharge properties of $\mathrm{LiCo}_{1 / 3} \mathrm{Ni}_{1 / 3} \mathrm{Mn}_{1 / 3} \mathrm{O}_{2}$ as a cathode for lithium secondary battery. The discharge curves of $\mathrm{LiCo}_{1 / 3} \mathrm{Ni}_{1 / 3} \mathrm{Mn}_{1 / 3} \mathrm{O}_{2}$ were measured from $2.5 \mathrm{~V}$ to $4.1 \mathrm{~V}$ at rate of indicated. As shown in Fig.4 (a), the s type of smooth line was plotted in the discharge curves. The discharge capacity of $\mathrm{LiCo}_{1 / 3} \mathrm{Ni}_{1 / 3} \mathrm{Mn}_{1 / 3} \mathrm{O}_{2}$ determined by discharge curves were 140 under the rate of $2 \mathrm{C}$ (current density of $2 \mathrm{~mA} / \mathrm{cm}^{2}$ ). These are higher than that of $\mathrm{LiCoO}_{2}$ and $\mathrm{LiMn}_{2} \mathrm{O}_{4}$. The discharge capacity decreased to $90 \mathrm{mAh} / \mathrm{g}$ under the rate of $10 \mathrm{C}$

The cycle performance for discharge of $\mathrm{LiCo}_{1 / 3} \mathrm{Ni}_{1 / 3} \mathrm{Mn}_{1 / 3} \mathrm{O}_{2}$ was also examined. Figure 5 shows the relation between discharge capacity and cycle number at $25^{\circ} \mathrm{C}$. The discharge capacity gradually decreased with increasing cycle number. After 50 cycles, $90 \%$ of discharge capacity at first was maintained under the rate of $1 \mathrm{C} .80 \%$ of it was also maintained under the rate of $10 \mathrm{C}$.

The heat-resistance of $\mathrm{LiCo}_{1 / 3} \mathrm{Ni}_{1 / 3} \mathrm{Mn}_{1 / 3} \mathrm{O}_{2}$ was investigated by examined cycle performance at $80^{\circ} \mathrm{C}$.
Figure 6 shows the relation between discharge capacity and cycle number at $20^{\circ} \mathrm{C}$ and $80^{\circ} \mathrm{C}$ under the rate of $1 \mathrm{C}$ The discharge capacity decreased with increasing cycle number. The cycle performance at $80^{\circ} \mathrm{C}$ was much the same as that at $20^{\circ} \mathrm{C}$. It was found that the discharge of $\mathrm{LiCo}_{1 / 3} \mathrm{Ni}_{1 / 3} \mathrm{Mn}_{1 / 3} \mathrm{O}_{2}$ could be done at high temperature.

\section{CONCLUSION}

Various types of oxide nano-sized powders were successfully prepared by ultrasonic spray pyrolysis using arc plasma under the air atmosphere. As-prepared powders had uniform morphology with narrow size distribution. The chemical composition of $\mathrm{BaTiO}_{3}$ and $\mathrm{LiCo}_{1 / 3} \mathrm{Ni}_{1 / 3} \mathrm{Mn}_{1 / 3} \mathrm{O}_{2}$ nanopowders was good agreement with the starting solution composition. The crystallinity of as-prepared powders was low, but improved by calcined at more than $800^{\circ} \mathrm{C}$.

The dielectric constant and $\tan \delta$ of $\mathrm{BaTiO}_{3}$ ceramics obtained from nanopowders was about 2000 and 0.025 at $25^{\circ} \mathrm{C}$, respectively. The discharge capacity of $\mathrm{LiCo}_{1 / 3} \mathrm{Ni}_{1 / 3} \mathrm{Mn}_{1 / 3} \mathrm{O}_{2}$ was $140 \mathrm{mAh} / \mathrm{g}$ and $90 \mathrm{mAh} / \mathrm{g}$ under the rate of $2 \mathrm{C}$ and $10 \mathrm{C}$, respectively. Discharge capacity of them decreased with increasing cycle number. The discharge of $\mathrm{LiCo}_{1 / 3} \mathrm{Ni}_{1 / 3} \mathrm{Mn}_{1 / 3} \mathrm{O}_{2}$ could be also done at $80^{\circ} \mathrm{C}$.

\section{References}

[1] G. L. Messing, S. C. Zhang and G. V. Javanthi, $J$. Am. Ceram. Soc., 76, 2707-26 (1993).

[2] H. Ishizawa, O. Sakurai, N. Mizutani and M. Kato, Am. Ceram. Soc. Bull., 65, 1399-1402 (1986).

[3] B. Dubois, D. Ruffier and P. Odier, J. Am. Ceram. Soc., 72, 713-15 (1989).

[4] B. Xia, I. W. Lenggoro and K. Okuyama, J. Mater. Chem., 11, 2925-27 (2001).

[5] Y. Ito and K. Okuyama, J. Ceram. Soc. Jpn., 111, 815-20 (2003).

[6] T.Kodera, H.Horikawa, T.Ogihara, N.Ogata, K.Nakane, S.Omura, M.Uede, K.Higeta and S.Hiyama, Electroceramics in Japan, 9, 135-138 (2006)

(Received December 10, 2006;Accepted January 31, 2007)

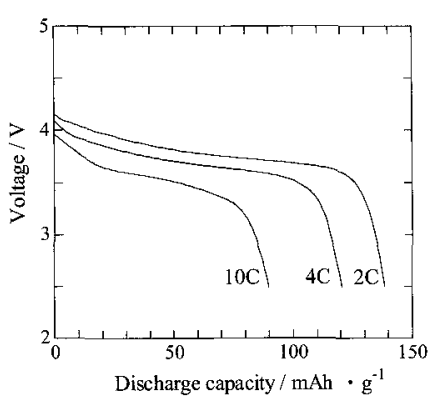

Fig. 4 Discharge curves at the rate of $2 \mathrm{C}$ to $10 \mathrm{C}$

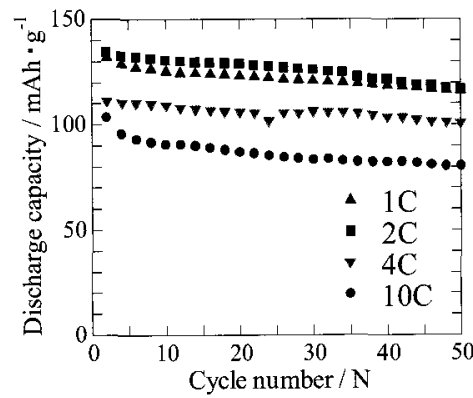

Fig. 5 Relation between discharge capacity and cycle number at room temperature

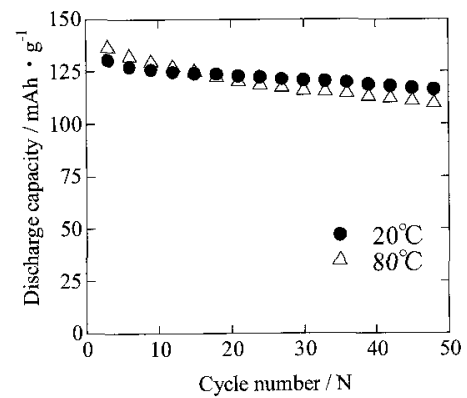

Fig. 6 Relation between discharge capacity and cycle number at $20^{\circ} \mathrm{C}$ and $80^{\circ} \mathrm{C}$ 